4. Kirschner M. Ein durch die Trendelenburgische Operation geheiter Fall von Embolie der Art. Pulmonalis. Arch Klin Chir. 1924;133:312.

5. Gibbon JH. Artificial maintenance of circulation during experimental occlusion of pulmonary artery. Arch Surg. 1937;34:1105

6. Swan H, Zeavin I, Blount SG Jr, Virtue RW. Surgery by direct vision in the open heart during hypothermia. JAMA. 1953;153:1081.

7. Allison PR, Dunnill MS, Marshall R. Pulmonary embolism. Thorax. 1960;15:273.

8. Berkas EM, Ferguson DJ, Garamella JJ, et al. Studies on techniques permitting prolonged cardiac venous inflow stasis. Surg Forum. 1953; 4:59-62.
9. Vossschulte K, Stiller H, Eisenreich F. Emergency embolectomy by the transsternal approach in acute pulmonary embolism. Surgery. 1965;58:317-23

10. Lam CR, Taber RE. Simplified technique for direct vision pulmonary valvotomy. J Thorac Cardiovasc Surg. 1959;38:309-18.

11. Mistrot J, Neal W, Lyons G, et al. Pulmonary valvulotomy under inflow stasis for isolated pulmonary stenosis. Ann Thorac Surg. 1976;21:30-7.

12. Cooley DA, Beall AC, Alexander JK. Acute massive pulmonary embolism. JAMA. 1961;177:283-6.

13. Sharp EH. Pulmonary embolectomy: successful removal of a massive pulmonary embolus with the support of cardiopulmonary bypass: case report. Ann Surg. 1962;156:1.

\title{
A primary aortoesophageal fistula due to esophageal carcinoma successfully treated with endoluminal aortic stent grafting
}

Yoshifumi Ikeda, MD, Naomi Morita, MD, Hideko Kurihara, MD, Masanori Niimi, MD, and Kota Okinaga, MD, Tokyo, Japan

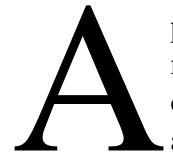

primary aortoenteric fistula is described as the communication between the aorta and the intestine without previous aortic surgery. Aortoesophageal fistula is a relatively rare but life-threatening cause of upper gastrointestinal tract bleeding. A thoracic aortic aneurysm is the most common reported cause, and ulceration of a carcinoma is a rarity. ${ }^{1}$ Although surgeons agree that the treatment of the primary aortoesophageal fistula should be surgical, the mortality is very high. Herein, we report a primary aortoesophageal fistula due to esophageal carcinoma successfully treated by using endoluminal aortic stent grafting.

\section{Clinical Summary}

A 64-year-old man was admitted to our department with persistent midthoracic pain, severe dysphagia, and a weight loss of $8 \mathrm{~kg}$ during the previous 3 months. An upper gastrointestinal endoscopic study revealed a friable tumor $5 \mathrm{~cm}$ in length in the middle thoracic esophagus. The esophageal tumor was diagnosed as a moderately differentiated squamous cell carcinoma by endoscopic biopsy samples. A computed tomographic scan revealed that the tumor invaded into the descending aorta. Therefore, the patient was treated with combination cis-dichlorodiammineplatinum and

From the Department of Surgery, Teikyo University School of Medicine Tokyo, Japan.

Received for publication July 15, 2005; revisions accepted Aug 26, 2005; accepted for publication Aug 30, 2005.

Address for reprints: Yoshifumi Ikeda, MD, Department of Surgery, Teikyo University School of Medicine, 2-11-1 Kaga, Itabashi-ku, Tokyo, 1738605, Japan (E-mail: yikeda@med.teikyo-u.ac.jp).

J Thorac Cardiovasc Surg 2006;131:487-8

$0022-5223 / \$ 32.00$

Copyright (C) 2006 by The American Association for Thoracic Surgery doi:10.1016/j.jtcvs.2005.08.042

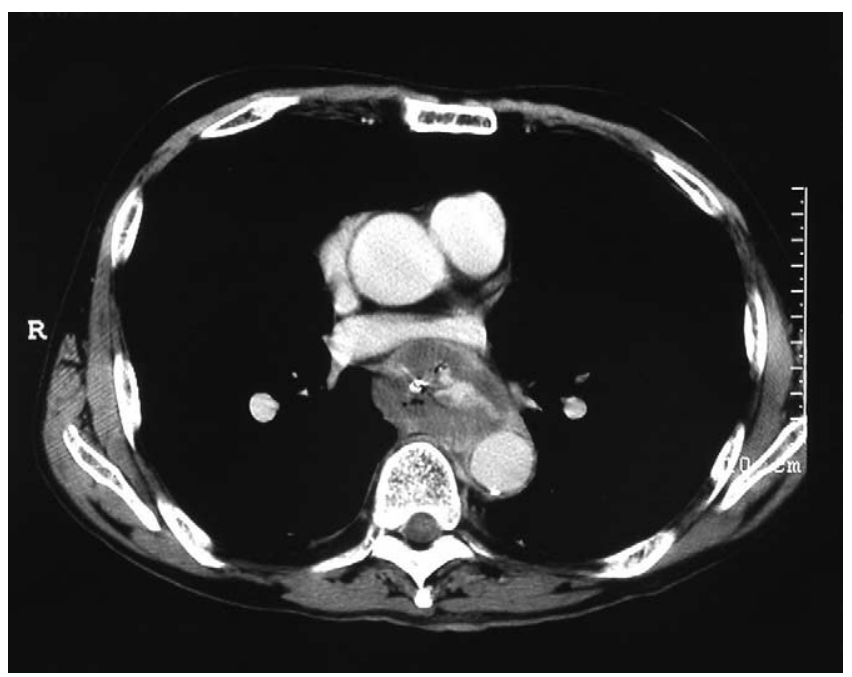

Figure 1. A computed tomographic scan revealed that the tumor invaded into the descending aorta and had a communication between the aorta and the esophagus.

fluorouracil adjuvant chemotherapy. The chemotherapy regimen consisted of $70 \mathrm{mg}$ of cis-dichlorodiammineplatinum on day 1 and $750 \mathrm{mg}$ of fluorouracil on days 1 to 5 , intravenously. Seven days after the chemotherapy, the patient experienced hemorrhagic shock with massive upper intestinal bleeding. After crystalloid transfusion, the patient recovered from the hemorrhagic shock. A computed tomographic scan and aortography were performed. Both tests showed a communication between the aorta $10 \mathrm{~cm}$ distal to the ostium of the left subclavian artery and the esophagus in its middle segment (Figure 1). To control massive upper intestinal bleeding, a stent graft made from a Gianturco Z-stent (William 


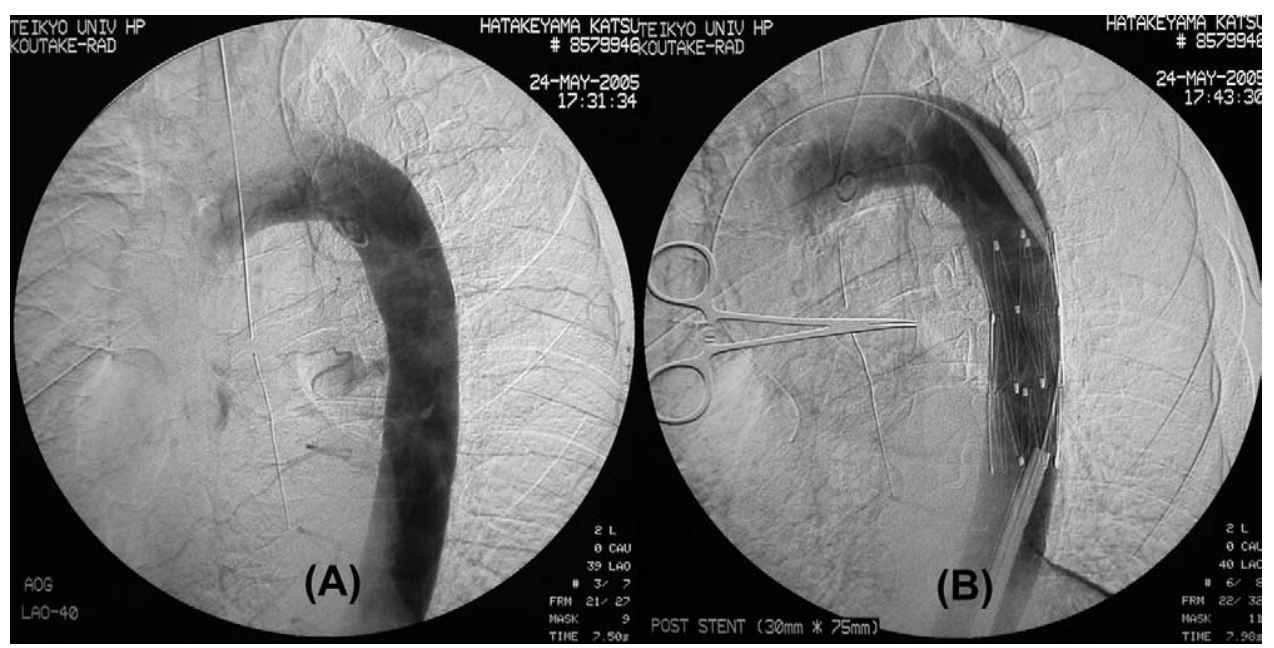

Figure 2. A, Aortography showed a communication between the aorta $10 \mathrm{~cm}$ distal to the ostium of the left subclavian artery and the esophagus in its middle segment. B, A stent graft made from a Gianturco Z-stent covered with a Dacron graft controlled massive esophageal bleeding.

Cook Europe A/S, Bjaeverskov, Denmark) covered with a Dacron (DuPont, Wilmington, Del) graft was implanted (Figure 2). After 2 weeks, the patient underwent bypass surgery by using the right colon replacement. The right colon was mobilized and then pulled through the cervical incision via the subcutaneous route. The cervical esophagus was cut with the linear stapler. The anastomosis between the proximal cervical esophagus and the ascending colon and the transverse colon and the stomach was performed in an end-to-side fashion. Subsequently, an end-to-end ileocolostomy was created. The patient's postoperative recovery was uneventful. At 6 months, he is enjoying a normal life and has been able to return to work.

\section{Comment}

Primary aortoesophageal fistula is a rare clinical entity, with an incidence in a necropsy series ${ }^{2}$ of $0.04 \%$ to $0.07 \%$. In 1991 , Hollander and Quick ${ }^{1}$ published a comprehensive review that included 500 cases of aortoesophageal fistula gathered from the literature. The main etiologic factor involved aortic disease; $54.2 \%$ of cases were secondary to rupture of an aneurysm of the descending thoracic aorta into the esophagus. The next most frequent causes were foreign body (19.2\%) and advanced esophageal carcinoma (17.0\%).

Many surgeons now agree that the treatment of the primary aortoesophageal fistula should be surgical, because patients treated conservatively have a high mortality. In 1969, Yonago and colleagues ${ }^{3}$ reported the first survivor of an aortoesophageal fistula. Since then, long-term survival has been obtained in patients with aortoesophageal fistulas secondary to foreign bodies, peptic ulceration, reflux esophagitis, thoracic aortic aneurysms, and posttraumatic inflammation. In 2000, Cairols and associates ${ }^{4}$ described a case of aortic perforation secondary to an esophageal carcinoma that was treated with initial success. Unfortunately, the patient died within a year of operation as a result of liver metastases. Because advanced esophageal carcinoma lesions are usually widespread and often have distant metastases, cases that have invaded into the aorta are deemed to be unresectable carcinomas when an aortoesophageal fistula has not occurred. Therefore, the best treatment of the primary aortoesophageal fistula due to esophageal carcinoma is unresolved.

Since Parodi and associates ${ }^{5}$ first reported the use of an endoluminal stent graft for repair of abdominal aortic aneurysms, use of the endoluminal stent graft procedure has expanded rapidly. We use this technique for the control of massive upper intestinal bleeding of an aortoesophageal fistula due to advanced esophageal carcinoma. The theoretical advantages of endovascular treatment of an aortoesophageal fistula are multiple. A simple arteriotomy is performed without thoracotomy or aortic clamping. The risk of medullar ischemia is theoretically less than that with conventional surgical intervention, possibly because of the absence of aortic clamping and the location of the aortic injury. Moreover, there is no need for intraoperative single-lung ventilation. Because stent graft insertion can be performed with mild anticoagulation, the major bleeding complications observed with heparinization can theoretically be avoided. Our experience demonstrates the effectiveness of endovascular graft placement and esophageal bypass reconstruction. This technique will find a role in the treatment of aortoesophageal fistula due to esophageal carcinoma.

\section{References}

1. Hollander JE, Quick G. Aortoesophageal fistula: a comprehensive review of the literature. Am J Med. 1991;91:279-87.

2. Dossa CD, Pippinos II, Shepard AD, Ernst CB. Primary aortoenteric fistula: part II. Ann Vasc Surg. 1994;8:207-11.

3. Yonago RH, Iben AB, Mark JB. Aortic bypass in the management of aortoesophageal fistula. Ann Thorac Surg. 1969;7:235-7.

4. Cairols MA, Izquierdo LM, Barjau E, Iborra E, Romera A. Primary aorto-oesophageal fistula due to oesophageal carcinoma. Report of a successfully managed case. Int Angiol. 2000;19:290-3.

5. Parodi JC, Criado FJ, Barone HD, Schonholz C, Queral LA. Endoluminal aortic aneurysm repair using a balloon-expandable stent-graft device: a progress report. Ann Vasc Surg. 1994;8:523-9. 